\title{
A Comparative Study of English Language Planning and Policy for Senior Secondary Education between Mainland China and Hong Kong
}

\author{
Buhan Pan \\ School of Foreign Languages \\ Huazhong Agricultural University \\ Wuhan, Hubei, China, 430070 \\ e-mail: panbuhan@163.com
}

\begin{abstract}
This paper intends to discuss English language policies in senior secondary schools in Mainland China and Hong Kong. First, we will focus on Mainland China in tracing the development of English language planning and policy in senior secondary education, and analyze the pros and cons of the latest English curriculum. Second, we will trace and analyze English planning and policy of Hong Kong in the same sequence. Third, we will make a comparison between language policies across the English curricula on both sides. Finally, we will try to propose an English language plan to relevant policy makers in Mainland China.
\end{abstract}

Keywords-language plan; senior secondary education; policy maker; English curriculum

\section{ENGlish LANGUAGE PlanNING AND POLICY DEVELOPMENT IN MAINLAND CHINA}

Weinstein [1] defines language planning as "a government authorized and conscious effort to alter a language's function in a society for the purpose of solving communication problems." Therefore the primary purpose of implementing a particular language policy is to encourage communication and interaction. Since both Mainland China and Hong Kong have experienced great changes in the modern history, it is important to first identify and explain the English language planning and policy development in these two areas.

China has a long history of more than 100 years on English language planning and education. At the very beginning, learning English was primarily out of practical purpose for Chinese. Zhidong Zhang, a famous educator in modern China, proposed his well-known principle of Chinese learning for fundamentals, Western learning for practice, which had been serving as a basis for learning English as a foreign language in China throughout the early years of the 20th century. English was officially brought into the syllabus of secondary schools for the first time in 1902 when China was in the late period governed by the Qing Dynasty. The English syllabus was named His Majesty's Teaching Standards for Secondary Institutions, which focused on teaching some basic English knowledge such as grammar and vocabulary (Curriculum Standards and Teaching Syllabuses for Chinese Primary and Secondary Schools in the $20^{\text {th }}$ Century: The English Volume,
1999) (hereafter Curriculum, 1999). Boyle [2] pointed out that at that time English was learned mainly in the way of imitation and repetition, which was the norm for the following many years.

During the period of the Republic of China (1911-1949), the Ministry of Education which was under the control of the government of the Republic of China was responsible for designing primary and secondary (both junior and senior) school syllabuses for English language. In 1923, it announced the English Language Teaching Syllabus for Senior Middle Schools under the New Teaching System. English was first required to be taught as a compulsory course in senior middle schools. And also for the first time, speaking and writing skills were included in the syllabus (Curriculum, 1999). Later the syllabus had been modified for five times before 1949, in the year of 1929, 1932, 1936, 1941 and 1948 respectively. There was no significant change in these modified editions of syllabuses for English language in senior secondary schools, however, one noticeable addition to the 1948 syllabus was that one aim of teaching English in senior middle schools was to stimulate students' patriotism and improve their understanding of foreign countries through learning the histories of western countries (Curriculum, 1999).

The year of 1949 can be considered as a watershed year in the history of China and also in the history of English language planning policy in schools in China. Language education had to serve the proletarian purpose [2]. The Ministry of Education of the People's Republic of China issued a whole new Draft Standard for English Curriculum in Senior Secondary Schools in 1951, in which the goal of English language learning was clearly stated as a tool for better serving the New Republic. However, at that time, English was not the main foreign language taught and learnt in China, since Russian, the language of the former Soviet Union, weighed more as a foreign language in school teaching. But with China's worsening relationship with the former Soviet Union in the following years, Russian finally ceased to be a foreign language taught in Chinese schools, and in the late 1950s, it was replaced by English [3]. Meanwhile, since the government of China realized the importance and urgency of opening up to the outside world, the position of English which was the major 
language spoken in most developed countries in the Western world was noticeably raised to a higher level in China. In 1963, the Ministry of Education drew up and issued the most comprehensive syllabus for English language in secondary schools since the founding of China. It was named Teaching Syllabus for English Language in Full-time Secondary Schools. It required students to further master a vocabulary of 2000 words and phrases upon completion of three-year senior secondary school studying (Curriculum, 1999). One noticeable addition in this syllabus was that materials on the culture of the English speaking countries were required to be included in the English courses by the Ministry [2], which could be seen as a sign of better days coming for English language teaching in China [4]. Unfortunately, the "better days" for English language teaching and learning were stopped by the disastrous Cultural Revolution which had lasted for more than one decade till 1978. During this period, English was banned from schools at all levels. In 1978, the year of the end of the Cultural Revolution, the Ministry of Education held an important conference on foreign language teaching, and issued the new Teaching Syllabus for English Language in Ten-year Full-time Primary and Secondary Schools (Draft). English was given prominence again in senior secondary schools. In the same year the Third Plenary Session of the $11^{\text {th }}$ Central Committee of the Communist Party of China marked the beginning of China's reform and opening-up policy, which could also be regarded as a vital policy for English language planning in China. With the opening up of Chinese markets and more and more foreigners being allowed to come into China to do business, the desire and need for learning English had never been so strong and urgent for Chinese people, especially in big cities such as Beijing and Shanghai. By the early 1980s English had been restored as a compulsory subject in the college entrance exam [2]. Thus much more importance was attached to English teaching and learning in senior secondary schools in China from then on.

In 1993, the Ministry of Education issued the Teaching Syllabus for English Language in Full-time Senior Secondary Schools (First Draft). This is the first time that the teaching syllabus for English language in senior secondary schools was separated from that for junior middle schools in China. The Syllabus particularly stressed on cultivating and improving students' ability in English reading skill. There was a significant addition to the teaching aims in this syllabus, that is, the communicative competency of English language both orally and in written texts was mentioned (Curriculum, 1999). It was in accordance with the central government's opening up policy which encouraged the communication with western developed countries, such as the United States and Britain.

Maley (as cited in [2]) says: "China is in a phase of industrial, scientific and commercial expansion which will make it the world's largest economy by the early years of the next century. In order to function efficiently in this role, it needs to bring large numbers of its people to high levels of proficiency in the use of English for a wide variety of functions". The fact proved Maley's prediction to be true. Upon entering the new millennium, the Ministry of Education issued the English Language Teaching Syllabus in Full-time Senior Secondary Schools, which was modified based on the 1993 version. At the very beginning of the syllabus, it emphasized the importance of English as a tool of international communication in the $21^{\text {st }}$ Century (Curriculum, 1999). Since the students in senior middle schools in China have to take the National Matriculation English Test (NMET), which does not include a speaking test, at the end of their senior middle school studying, the Syllabus still paid much attention on basic English skills like listening, reading and writing. The latest syllabus (trial) for Chinese senior secondary schools was issued in 2003, which was named English Curriculum Standards for Senior Secondary Schools. It clearly stated that the English teaching should put stress on the following four aspects: developing students' abilities of applying English pragmatic knowledge; improving their abilities of making appropriate communication by using English; improving their abilities of acquiring and processing information; and cultivating their abilities of logical thinking via English (Curriculum, 1999). As we can see from the latest Standards, communicative competency has been paid more and more attention by the official government as a useful tool for future development. Just as Cowan et al. [5] predicted in their study, English would be studied and used primarily as a necessary tool which could facilitate access to modern scientific and technological advances, and as a vehicle to promote commerce and understanding between the country and the world in the future.

\section{ANALysis OF The LATESt LANGUAGE PlanNING AND POLICY IN MAINLAND CHINA}

Compared with the previous curriculum design, there are some improvements in the latest syllabus. Firstly, it was based on the present situation of the English teaching of our country [2]. In consideration of the need of opening policy, future development and the increase of the overall national strength, the syllabus tried hard to achieve the goal of advanced conception and high practicality. Secondly, the cultural and functional feature of foreign language course was stated more clearly, and language education as a very important part of the education of all-round development was also stressed. The necessity to learn language, culture and ideology at the stage of secondary senior school was set to enrich the target of language learning. Thirdly, the syllabus reflected both integral and elemental qualities of the fundamental English education. Meanwhile, it is in accordance with the need of individuality and diversification of senior secondary school students. In order to fulfill the requirements mentioned above, obligatory and elective courses are designed with a credit system as a model in the basic unit of English teaching [3].

Fourthly, the syllabus brought up an idea that English teaching in senior secondary school should develop students' English ability such as the ability to communicate fluently in English, the ability to get useful information in English, the ability to think in English. These abilities were designed to help students to get prepared for the coming university study. Fifthly, the syllabus made clear the focus of high school English teaching and promoted the change of study mode of students and teaching mode of teachers respectively. The syllabus pointed out that the English course of senior secondary school was the development of compulsory education and also a very important part of the elemental education. It focused on the training of all kinds of language abilities of students and encourages the teachers to change the 
traditional ideas of teaching. It emphasized that teachers should pay attention to the future development and students needs [2]. Sixthly, in order to encourage students to develop their English ability, the English Curriculum Standards for Senior Secondary Schools also designed a relatively mature assessment system to evaluate the students' learning English, which served the goal of encouraging and promoting the study and help them to develop individual interests and other practical abilities. It also brought up the idea that the evaluation should employ different styles in order to accommodate to different characteristics of required courses and elective courses. In the suggestions to evaluation, both evaluation principles and comparatively detailed cases and quota were put forward for teachers' reference. At the same time, it also provided relatively specific guidance and suggestions towards methods of assessments. Finally, according to the regular pattern of English learning and the request of English ability, the syllabus brought up the idea of setting up a system of elemental English education level certificate. Generally speaking, a student should achieve a certain level before graduation. Students who have interests or potential in English learning can attend the elective course and many other kinds of courses according to their personal needs. The course design dropped the old way that required all the students to reach the same level, and introduced a more flexible and advanced mode.

However, the English Curriculum Standards for Senior Secondary Schools bears some flaws that need to be improved. First of all, the articles chosen in the textbooks are not very interesting and practical. Most texts are narrative essays which are lack of fun and beauty of language. Listening and speaking materials are not authentic and up-dated. Besides, the conversations in the materials were always designed as an ancillary of the main text, and the contents were simple repetition in most occasions. In order to raise students' enthusiasm on learning English and to help the students in developing all-round English abilities, course designers had better modify and improve the textbooks [5]. Secondly, although the syllabus mentioned that understanding the cultural background was a very important part in English learning, the types and contents of texts were relatively unitary on the contrary. It would serve the goal better when more literature components are added to textbooks such as some classical prose, poetry, reviews, plays or novels. This kind of change can not only attract the students' interest in learning English, but also improve their humanism equipment. Next, the syllabus still put too much emphasis on the grammar part; as a result, the English teaching in mainland senior secondary schools still paid too much attention on this part. Fourthly, although the English Curriculum Standards for Senior Secondary Schools provided some elective courses, in fact few students would like to take extra courses, because most students have great pressure of entering into a good university, and there are other subjects they should work hard on. Only some excellent students would like to pursue higher achievement in English language.

\section{ENGLish LANGUAGE PlanNING AND POLICY DEVELOPMENT IN HONG KONG}

English was the language the British colonists brought to Hong Kong some 150 years ago. Now English has been more widely used in certain domains such as government administration, commerce, education etc. English language teaching (ELT) in Hong Kong had been shaped to support English-speaking elite for government and commerce $[6,7,8]$. Here, we will focus on the English language planning and policy in Hong Kong from the perspective of English language curriculum in secondary schools, and the emphasis will be laid on secondary 4-6, which is the counterpart of the three-year senior secondary schooling in Mainland China.

First, we will look at the different stages of English language curricula set by the Hong Kong Curriculum Development Council (hereafter CDC). After the World War II, the ELT methodology in Hong Kong focused mainly on the forms of English so that students would learn to make correct sentences based on their conscious awareness of the forms and rules governing the English use. In the early 1970s, the oralstructural approach became the dominant method practiced, in which the primary emphasis was on providing students with sufficient chances for repetitive practices of the structural patterns of the language (CDC, 1983). However, though students might be able to gain a high score in the tests, their ability to communicate in English was questionable. The rise of communicative language teaching also had impact on the ELT approach promoted by the Education Department in HK in the 1980s. Thus the teaching emphasis shifted from formal structure of English to functional uses of English.

Less than 20 years after communicative language teaching appeared in the government curriculum documents, and before its successful implementation could be ascertained, the latest target-oriented (in the early 1990s) and task-based (in the late 1990s) ELT approach being promoted by the Education Department characterized "leaner and learning-centered". Target-oriented curriculum was introduced in 1993, which placed greater emphasis on learning targets and the process of purposeful and contextualized learning, and laid the foundation for a task-based, process-oriented, learner-centered and a more integrated approach. The focus was mainly on classroom interaction and student participation. Classroom environments were characterized by learner-centered notions and task-based or problem-solving approach.

The major English language syllabuses for secondary schools in Hong Kong are illustrated as follows. In 1975, CDC issued the Provisional Syllabus for English (Forms 1-5). The teaching of the four skills - reading, listening, writing, speaking was clearly described and illustrated. English language teaching focus was on structural knowledge, and accuracy was emphasized in speech before writing. In 1983, Syllabus for Secondary Schools: English (Secondary 1-5) was published. Similar to the 1975 Syllabus, the four skills were described, activities suggested and rationale explained. Ways of assessing students were given with concrete examples.

The year of 1997 saw a significant change in the history of Hong Kong. Hong Kong became a special administrative region of the People's Republic of China. However, the political change didn't have a great impact on English language planning and policy in Hong Kong secondary schools. Evans [9, 10] stated that the Education Department still placed much emphasis on the British way of language teaching, which had 
been regarded to be effective for the English language classroom teaching in Hong Kong. In 1999, CDC issued the Syllabus for Secondary School - English Language (Secondary 1-5). This was a continuation of the primary school syllabus. The forms and functions including text-types, vocabulary, language items, skills and strategies were clearly spelled out. Ways to conduct a reading task or writing task were given.The Syllabus emphasized the role of a second language in personal, social, intellectual and educational development and aimed to enable the learners to develop an ever-improving capability to use English to think and communicate, to acquire, develop and apply knowledge, to respond and give expression to experience and within these contexts, to develop and apply an everincreasing understanding of how language was organized, used and learned.

In 2001, CDC contemplated the previous syllabuses and published a book, Learning to Learn-The Way Forward in Curriculum Development. In the book, schools were encouraged to continue with the good practices that were already in line with the recommended curriculum developments, further to provide greater opportunities for learners to use English for purposeful communication both inside and outside the classroom, to make use of learnercentered instruction to encourage learner independence, to make greater use of literary/imaginative texts to develop critical thinking and encourage free expression and creativity and to promote strategies, values and attitudes that are conducive to effective, independent and life-long learning. In the following years of 2002, 2003, 2004 and 2006, CDC published the Education Commission's Education Reform Reports, Learning for Life, Learning through Life. In the reform reports, curriculum development and language education in secondary education were illustrated respectively, and later many of the recommendations became English language education policies [11].

The latest syllabus is the 2007 CDC-HKEAA Literature in English Curriculum and Assessment Guide (Secondary 4-6) and CDC-HKEAA English Language Curriculum and Assessment Guide (Secondary 4-6). The English Language Education in the new curriculum includes two subjects: Literature in English and English Language (Core subject). The two Guides are drawn up under the following background. They incorporate the key recommendations made in the CDC's Senior Secondary Curriculum Guide (2007) and Basic Education Curriculum Guide - Building on Strength (2002), the final report on its Holistic Review of the School Curriculum entitled Learning to Learn - The Way Forward in Curriculum Development (2001) and the Education Commission's education reform final report, Learning for Life, Learning through Life (2000). The latter four documents provide the overall direction for both education and curriculum development in Hong Kong now and in the years to come, and seek to facilitate the accomplishment of the principal educational aims of lifelong learning and whole-person development.

The Literature in English Curriculum and Assessment Guide (Secondary 4-6) (2007) is built on the existing literature curriculum for Secondary 4 -5 (S4-5) as well as the Advanced Supplementary Level (ASL) and Advanced Level (AL) literature curricula. The English Language Curriculum and Assessment Guide (Secondary 4-6) (2007) is built on the existing English language curriculum for Secondary 4-5 and Sixth Form Use of English. Following the general direction for the development of English language education curriculum set out in the English language Education Key Learning Area Curriculum Guide (Primary 1- Secondary 3) (2002), the two Guides extend the prior knowledge, skills and positive values and attitudes that learners develop through the English language curriculum, particularly in the area of language arts, for basic education from Primary 1 to Secondary 3 (P1-S3). The Guides delineate the aims, learning targets and objectives of the subject. They also provide guidelines, suggestions and exemplars to promote effective learning, teaching and assessment practices and to help school and teachers to plan, develop and implement their own school-based senior secondary English language education curriculum.

The overall aims of the two Guides are explained as follows. The Literature in English Curriculum and Assessment Guide (Secondary 4-6) (2007) is aimed to enable learners to appreciate and enjoy a wide range of literary or creative texts and other related cultural forms, to develop their capacity for critical thinking, creativity, self-expression, personal growth, empathy and cultural understanding, to enhance their awareness of the relationship between literature and society, to develop a greater sensitivity to the nuances of the English language, and to be adequately prepared for areas of further study or work, where qualities promoted in the study of literature, such as creativity, critical thinking and inter-cultural understanding, and highly valued. And the English Language Curriculum and Assessment Guide (Secondary 4-6) (2007) is aimed to provide learners with learning experiences to increase their language proficiency for study, work, leisure and personal enrichment, to develop their general and linguistic knowledge, language and communication skills, vales and attitudes, to promote lifelong learning so as to enhance their personal and intellectual development, cultural understanding and global competitiveness, and to enable learners to prepare for the changing socio-economic demands resulting from advances in information technology which include the interpretation, use and production of texts for pleasure, study and work in the English medium.

One of the original intentions of the new English language curriculum lies in improving teaching and learning in the classroom, especially improving language teaching and learning standards. But for various reasons, like other new things, the new curriculum comes into being with its pluses and minuses alongside. In the following part, we will analyze and discuss the pros and cons of the language planning and policies by looking at the latest English Language Curriculum and Assessment Guide (Secondary 4-6) and the Literature in English Curriculum and Assessment Guide (Secondary 4-6) released in 2007, which partly reflect the new development of English language planning and policy of Hong Kong.

\section{ANALYSis OF THE LATEST LANGUAGE PlanNING AND POLICY IN HONG KONG}

There are three advantages of the new Guides. First of all, students will be better prepared for work or further learning, 
and students will enhance language abilities, broaden knowledge base, and increase competence in critical thinking, independent learning and interpersonal skills. And they can be exposed to other learning experiences in moral, civic, physical an aesthetic areas. The new curriculum will provide smoother pathways for students to get higher education qualifications so that every student has an opportunity to succeed in life. Secondly, the 2007 curriculum is a further move to enhance student-centered English language teaching after the previous curriculum. It focuses on "learner" and "learning" rather than "teaching". In the latest flexible and diversified curriculum, students, with all their entitlement to learning opportunities, are expected to be active learners negotiating the learning process and outcome with their teachers. Essentially, the students change their roles from passive recipients to active constructors of knowledge. Therefore, the new curriculum caters for a wide spectrum of students' interests, needs and abilities and hence may exert positive impact on their learning. Thirdly, the 2007 curriculum emphasizes specially on meaningful communication and purposeful interaction. Hence activities are designed to provide the maximum opportunities for students to use both oral and written English. Such activities also give the context for teaching grammar and other language features. It promotes English language teaching in a comprehensive way. Thus, the two Guides, if implemented successfully, can help the students equip with sufficient English knowledge, and will prepare the secondary school graduates' with adequate English proficiency and pave the way for their work or further education.

However there are still some disadvantages of the two Guides. Firstly, there are some problems in the implementation of the initiative of the new curriculum. According to Kwan and Hingman [11], education policy and curriculum decisions in the Hong Kong context are mainly formulated by the local government through different agencies such as CDC and the Education Commission. The initiative of the new curriculum is largely a top-down process of curriculum renewal, with $\mathrm{CDC}$ serving as the initiator of the new language curriculum and English teachers as implementers. Despite the fact that there are teachers and principal representatives in major advisory committees, the degree to which they can exert influence on policy making is questionable within such a centralized decision-making process. In recent years, while consultation exercises appear to improve the new curriculum, such exercises were just routinely conducted before the launching of any important policy, which is expected to be put into effect by schools and brought into practice by language teachers. In the current case of 2007 English language curriculum, there are also some mismatches between the intended and the implemented curriculum. Inevitably, such a top-down means of policy making and implementation to certain extent weakens the support from schools and teachers for the new curriculum.

Besides, to support the implementation of the 2007 curriculum, the Education Commission and related organizations will run massive in-service secondary English teacher development course programs. These courses are intended to enhance teachers' understanding of the new curriculum for effective implementation of the latest curriculum. However, it is questionable whether the teachers can familiarize and adapt to the new curriculum and adjust their teaching strategies only through short programs. Moreover, examinations always have an important status at all levels of education, and it is particularly true in HK secondary senior schools. For the secondary senior students, they are selected for higher education through examination, which is quite high-stake. Therefore, examinations and tests are very critical parts of school life, and teaching becomes geared towards preparing students for examinations rather than nurturing students' potential and talent. While tests and examinations are effective and essential ways to assess teaching and learning, such assessment might also be one of the major obstacles in the implementation of the initiative of the curriculum [12]. This will be also true with the implementation of the 2007 English language curriculum. In the educational context of Hong Kong, where the product-oriented assessment is still widely practiced, there is still a long way to go to transform the stakeholders' orientation and educational practices in the language classroom for an attainment of the new 2007 curriculum. High expectations are held towards the 2007 curriculum, but it still takes time to wait and see its influences.

\section{COMPARISON OF LANGUAGE POLICIES IN MAINLAND CHINA AND HONG KONG}

When we compare English language policy concerning senior secondary education in Mainland China and Hong Kong, we tend draw our focus on their English curricula which clear demonstrate the similarities and differences in their policies. Another consideration is that there are a lot of things that can be compared, so we only choose some important aspects in English language education to compare for the purpose of reflecting the latest development in the area and benefiting language planners and educators on both sides.

\section{A. Similarities}

According to the Senior Secondary Curriculum Guide (SSCG) (2007), the general layout of the senior secondary education consists of three years named Secondary 4-6. This means that Hong Kong gradually shifts from a Key Stage 4 plus Six Form mode into a three-year mode of senior secondary which is similar to the situation in Mainland China.

Both syllabi in Mainland China and Hong Kong emphasize on the training of four basic language skills: listening, speaking, reading and writing. Specific descriptions of different levels are provided, which not only clarify the goals of teaching, but also provide guides for learners. This similarity shows that in the early stage of language learning, skill training is not only helpful for future development, but also necessary.

To compare the two latest versions of course curriculum on both sides, the development of communicative ability in language learning is emphasized. Though the communicative language teaching has been introduced to Mainland China and Hong Kong for more than ten years, Hong Kong has even gone one step further by implementing target-oriented curriculum, the transforming ideas in educators' mind from both sides are more or less the same. We should not focus too much on teaching the forms of English, but the functions of the language. We should not let students learn to memorize the language, but 
rather use it properly. We should not let teachers dominate the classroom; teaching should be student-centered.

Considering the scope of abilities mentioned for development in both sides' syllabi, they not only cover the development of language knowledge and skills, but also suggest that teachers should help students develop their cultural knowledge, strategies and affective abilities in learning.

\section{B. Differences}

The 2007 English curriculum in Hong Kong includes two core subjects: Literature in English and English Language, and some electives for students to take. This is quite different from the situation in Mainland China whose curriculum only offers one required course. Though there is a tendency in Mainland China that some key schools at provincial level have already provided extra electives for students to choose, for most secondary schools this is impossible to implement due to limited resources. On the whole, secondary schools in the mainland have a very unified and rigid standard for English education, and intend to fulfill all the teaching targets within a single course. In a sense, all the students walk on the same path for the same goal, which ignores personal differences in language development. The English education in Hong Kong, on the other hand, pays more attention to various ways and aspects of language learning, thus more flexible.

According to the 2003 English Curriculum Standards in Mainland China, to improve students' communicative competence is regarded as a prime goal of teaching. However, the curriculum does not provide clear and detailed descriptions of the abilities that teachers should focus. In practice, teachers in the mainland still tend to emphasize on the language knowledge itself, while in Hong Kong teachers pay more attention to cultivating students' abilities to use language in the contexts.

Another big difference between English curricula on both sides lies in the assessment system. In the English curriculum of Hong Kong, detailed measurements are explained. The assessments tend to evaluate various abilities scientifically, and a lot of attention is given to classroom assessment. An oral exam is always included in the assessment system, while it is often ignored in Mainland China. As to large-scale exams, a standardized English test emphasizing total scores is used in Mainland China as a section of National College Entrance Exams, which often fails to provide beneficial washback to students' learning. Though some changes occur in the assessment system [2], there is still much room for improvement.

In teaching, various methods are used to encourage students to participate in learning. Presentations and group discussions are frequently used to arouse students' interest as well as push them to use English in communicative activities. The variety of teaching methods has not been given enough attention in Mainland China, since teachers tend to dominate the class and use the same mode of methods to teach.

In addition, there are some differences in teaching materials and textbooks for senior secondary schools. In Hong Kong, teachers may have more updated and systematic materials to prepare for lessons, while in Mainland China, some schools even do not have sufficient textbooks. Another thing concerns the quality of texts chosen in the books. Some materials in Mainland China's textbooks are outdated and uninteresting, while the textbooks in Hong Kong pay much attention on the authenticity of language use. Besides, the speed of learning materials updating is faster in Hong Kong.

Similarities display some basic principles in curriculum design and language learning, but differences can really reflect some contextual reasons and policy-making ideals in Mainland China and Hong Kong. For the benefits of learning from each other, especially to propose a language plan for Mainland China officials, we should pay more attention to the differences and try to figure out the things that we can learn from.

\section{AN ENGLISH LANGUAGE PLAN FOR POLICY MAKERS}

The effects and results of English teaching shows that Hong Kong's ESL teaching does better than EFL teaching in mainland. Despite of the differences, mainland and Hong Kong still bear a lot in common with regard to the contexts of English language teaching. Thus as for the policy makers in China, they may draw some lessons from Hong Kong for reference. We will propose an English language plan for the senior secondary school level to the policy makers in mainland in the following.

Firstly, the latest syllabus (Trial) for Chinese senior secondary schools issued in 2003 clearly states that the English teaching should put stress on improving their abilities of making appropriate communication by using English. In this latest curriculum, communicative competency has been attached more attention than before. For long, the EFL teaching in mainland focus on a lot on reading, with increasing importance of writing and listening. Cultivating the students' English speaking skill has been always a neglected part in the real teaching practice. The reason for the existence of such situation is probably that there has been not any tests assessing speaking or include the assessment of speaking. Given that examination-oriented education is still an ingrained part of Chinese Heritage Cultures, therefore if the government gives prominence to students' communicative competency, then corresponding tests, especially those high-stake ones, should be offered meantime to effectively assess and assure students' development of the oral communicating skill.

Secondly, the mainland English teaching used to neglect the literature education of the students but pay too much attention on grammar teaching and ask the students to practice all kinds of grammar points once and once again. The result is the students are fed up with English and cannot realize the beauty of this language. Add some literature elements to the course will arouse the learning interest of students and help them to understand English culture. In consider of the objective condition of mainland English teaching, it is not very possible to make English literature as a separate course, but it is still possible to add some literature works into the textbook.

Thirdly, early in 2000, the concept of "Learning for Life, Learning through Life" was raised in the Education Commission's education reform final report. The document provides the overall direction for curriculum development in Hong Kong for recent years. Mainland can draw lessons with 
regard of such teaching, or put it more exactly, learning concept. EFL education in China has been largely focused on classroom teaching and learning. Although mainland is not as internationalized as Hong Kong, it is still quite open. Outside classroom, abundant opportunities are unfolded for students to learn English, even when they are shopping or dining. By learning through life, students can learn English in a vivid way closing to their own experience, thus English acquired in such way can leave a deep impression in their brain and easy for them to activate and make use in their output. In the next new coming English language curriculum, encouraging the students to learn English in a more flexible way should be mentioned and attached importance.

Fourthly, the mainland course designers should also learn the way of assessment from Hong Kong. Especially the principles like timely and encouraging feedback, marking reference to the school's context and to current progress of students' study. Mainland secondary schools generally have two big examinations (mid-tern exam and final exam) and some irregular class progress tests in one semester. Since sometimes these assessments cannot provide a satisfactory feedback, the mainland course designers would better draw on some experience from Hong Kong.

Fifthly, English course design should pay more attention to the individual differences of learners and their different needs in learning. Students should be encouraged to pursue their personal development through their own learning strategies. Teachers should use various teaching methods to fit different groups of students.

\section{CONCLUSION}

Through the comparison and contrast between English language planning and policy for senior secondary education in Mainland China and Hong Kong, our understanding of language policy across the curriculum is deepened. We become fully aware of the importance of language policies and their impacts on teaching and learning. If educational policy makers can learn from each other, English teaching will be greatly improved.

\section{ACKNOWLEDGMENT}

This research was financially supported by the Humanities and Social Science Project of Hubei Province (2012G171) and the Teaching Reform Project of School of Foreign Languages in Huazhong Agricultural University (2014).

\section{REFERENCES}

[1] B. Weinstein, "Language planning in Francophone Africa," Language problems and language planning, vol. 4 (1), 1980, pp. 55-77.

[2] J. Boyle, "A brief history of English language teaching in China," IATEFL Issues, vol. 155, 2000, pp.14-15.

[3] L. Jin and M. Cortazzi, "English language teaching in China: A bridge to the future," in English language teaching in east Asia today, W. K. Ho and R. Wong, Eds. Singapore: Eastern Universities Press, 2004, pp. 119134.

[4] R. Price, "English teaching in China: Changes in teaching methods from 1960-66," English Language Teaching Journal, vol. 26(1), 1971, pp. 7183.
[5] J. Cowan, R. Light, B. Mathews, and G. Tucker, "English teaching in China: A recent survey," TESOL Quarterly, vol. 12 (4), 1979, pp.465482.

[6] G. A. Postiglione, Education and society in Hong Kong: Towards one country and two systems. Hong Kong: Hong Kong University Press, 1992.

[7] A. E. Sweeting, "Hong Kong education within historical processes," in Education and society in Hong Kong: Towards one country and two systems, G. A. Postiglione, Ed. Hong Kong: Hong Kong University Press, 1992.

[8] E. A Walker, "An analysis of changes in the aims and objectives of the secondary English syllabi (1975-1999)," in School curriculum change and development in Hong Kong, Y. C. Cheng, K. W. Chow, and K. T. Tsui, Eds. Hong Kong: Hong Kong Institute of Education,1999.

[9] S. Evans, "The context of English language education: The case of Hong Kong,” RELC, vol. 27, 1996, pp.30-55.

[10] S. Evans, "Teacher and learner roles in the Hong Kong English language classroom," Educational journal, 25(2), 1997, pp.43-61.

[11] C. W. Kwan and M. C. Hingman, "English language teaching in China: A bridge to the future," in English language teaching in east Asia today, W. K. Ho and R. Wong, Eds. Singapore: Eastern Universities Press, 2004, pp. 150-177.

[12] W. S. Y. Wong and M. Y. M. Pang, "An Analysis of the Primary English Curriculum: Mismatches and Implications," in School Curriculum Change and Development in Hong Kong, Y. C. Cheng, K.W Chow, and K.T. Tsui, Eds. Hong Kong: Hong Kong Institute of Education, 1999. 